Revue d'histoire de l'Amérique française

RAS REVUE D.HISTOIRE DE L'AMÉRIQUE FRANÇAISE

\title{
Ce qu'est la Fondation Lionel-Groulx et le Centre de recherche Lionel-Groulx
}

Volume 30, numéro 4, index, mars 1977

Index des volumes XXI-XXX (juin 1967-mars 1977)

URI : https://id.erudit.org/iderudit/303579ar

DOI : https://doi.org/10.7202/303579ar

Aller au sommaire du numéro

Éditeur(s)

Institut d'histoire de l'Amérique française

ISSN

0035-2357 (imprimé)

1492-1383 (numérique)

Découvrir la revue

Citer ce document

(1977). Ce qu'est la Fondation Lionel-Groulx et le Centre de recherche Lionel-Groulx. Revue d'histoire de l'Amérique française, 30(4), 151-153. https://doi.org/10.7202/303579ar d'utilisation que vous pouvez consulter en ligne.

https://apropos.erudit.org/fr/usagers/politique-dutilisation/ 


\section{CE QU'EST LA}

\section{FONDATION LIONEL-GROULX \\ ET LE CENTRE DE RECHERCHE LIONEL-GROULX}

La Fondation Lionel-Groulx est une corporation légalement constituée par lettres patentes du 17 mai 1956

La Fondation a été mise sur pied par des amis du chanoine Lionel Groulx pour:

- encourager la recherche en histoire de l'Amérique française;

- maintenir et développer un centre d'étude et de recherche dans ce domaine;

- stimuler l'intérêt pour l'histoire par des concours d'histoire et donner des bourses pour recherches;

- éditer certains manuscrits;

- assurer la survie de l'œuvre de Lionel Groulx et de sa Revue d'histoire de l'Amérique française, périodique trimestriel publié déjà depuis 30 ans.

\section{Qui dirige la Fondation Lionel-Groulx?}

La Fondation Lionel-Groulx, société sans but lucratif, est dirigée actuellement par les membres suivants:

président: $\quad$ Dr Jacques Genest, C.C., M.D., FSRC, directeur de l'Institut de recherches cliniques de Montréal

vice-président: Roger Charbonneau, président de l'Anglo-French Drug; président du Comité de planification aux HEC et directeur du Centre d'études en administration internationale

administrateurs: Richard Arès, s.j., président de l'Académie des sciences morales et politiques

Roger Larose, vice-recteur à l'administration, Université de Montréal 
Rosaire Morin, président du Conseil d'Expansion économique

trésorier: Joseph-A. Dionne, ing., président de la Caisse populaire d'Outremont; administrateur de la Fédération des Magasins COOP

secrétaire: Juliette Rémillard, directeur du secrétariat de l'IHAF

Le premier président de la Fondation fut Me Maxime Raymond auquel succéda Me Joseph Blain.

\section{Activités de la Fondation Lionel-Groulx}

Depuis 21 ans, la Fondation a maintenu et développé le Centre de recherche Lionel-Groulx, dans la maison autrefois habitée par le chanouine Lionel Groulx, au 261 avenue Bloomfield, Outremont, et que ce dernier a léguée à la Fondation par testament.

De nombreux chercheurs du Canada, des États-Unis et d'ailleurs sont venus et viennent consulter les documents d'une richesse exceptionnelle qui y sont accumulés. Ce Centre est le seul institut privé de recherche en histoire de l'Amérique française. La Fondation y conserve les manuscrits, la correspondance et les archives du chanoine Lionel Groulx, de Me Maxime Raymond, de Me Antonio Perrault, d'André Laurendeau, de Georges Pelletier, de Michel Brochu, de Léo-Paul Desrosiers, de L.-A. Fréchette, de René Desmarais, et autres. On y trouve aussi des documents spéciaux sur J.-J. Girouard, Louis-Joseph Papineau, les patriotes de 37, l'Action française, l'ACJC, le Bloc populaire canadien, les États généraux du Canada français, la Ligue pour la défense du Canada, les JeuneCanada, etc.

La Fondation possède une bibliothèque spécialisée en histoire d'environ 12,000 volumes et de 4,000 brochures (avec système de fiches), mise à la disposition des chercheurs. Un grand nombre de thèses de maîtrise et de doctorat ont été facilitées par la consultation des documents du Centre.

De plus, la Fondation maintient la maison (ou siège social) léguée par le Chanoine dans le meilleur état possible, y fait les réparations nécessaires et paie les taxes et l'entretien. Elle contribue au financement de la Revue d'histoire de l'Amérique française en lui assurant un secrétariat permanent ou siège social. 
À maintes reprises, la Fondation Lionel-Groulx a accordé, dans le passé, un prix d'histoire du Canada à tous les collèges classiques.

\section{Divers projets}

Une mine documentaire aussi riche, recouvrant divers aspects très importants de l'histoire du Québec au XXe siècle et de l'histoire de l'Amérique française, est susceptible de s'accroître. La Fondation voudrait augmenter le matériel documentaire du Centre, faire l'acquisition de certains volumes d'histoire, de guides, de microfilms et de périodiques de diverses natures.

La Fondation songe aussi à recueillir, sur les personnages des divers fonds qu'elle possède et sur les fonds eux-mêmes, tout document, correspondance ou autre, susceptible de compléter cette documentation. Elle songe aussi à obtenir les papiers et documents des collaborateurs de Groulx, entre autres, et de tous ceux-là qui ont joué un rôle public au Québec depuis 100 ans, sans oublier les dossiers de divers groupements ou associations.

À maintes reprises, la Fondation Lionel-Groulx a accordé, dans le passé, un prix d'histoire du Canada à tous les collèges classiques. Pour encourager la recherche, elle voudrait enfin apporter à un chercheur sérieux l'appui financier dont il a besoin, et ce, sur une base de plusieurs années si nécessaire.

\section{CONCLUSION}

Toutes ces initiatives se présentent comme un défi à relever. Créer un climat d'initiative, c'est faire en sorte que l'étudiant ou le chercheur puisse œuvrer avec aisance et facilité. C'est à cette aspiration que tend la Fondation Lionel-Groulx. 